\title{
Application of Esterified Ogbono Shell Activated Biomass as an Effective Adsorbent in the Removal of Crude Oil layer from Polluting Water Surface
}

\author{
${ }^{1}$ ONWU, DO; ${ }^{2}$ OGBODO, ON; ${ }^{3}$ OGBODO, NC; ${ }^{1}$ CHIME, TO; ${ }^{1}$ UDEH, BC; \\ ${ }^{1}$ EGBUNA, SO; ${ }^{1}$ ONOH, MI; ${ }^{* 1}$ ASADU, CO
}

\author{
${ }^{1}$ Department of Chemical Engineering, Enugu State University of Science and Technology, P.M.B 01660 Enugu Nigeria, \\ ${ }^{2}$ OVH Energy Limited, Port Harcourt Nigeria \\ ${ }^{3}$ Mobil Producing Nigeria Unlimited, Lagos Nigeria \\ *Corresponding Author Email: aasadu@yahoo.com
}

\begin{abstract}
This work focuses on the removal of oil from polluted water surface using activated biomass such as ogbono shell. The shell was carbonized at a temperature of $600^{\circ} \mathrm{C}$ for $4 \mathrm{~h}$ and then further modified with stearic acid. Characterization of the adsorbent produced was carried out using Scanning electron microscopy (SEM) to study the surface morphology of raw and grafted ogbono shell. Fourier Transform Infra-red Spectroscopy (FTIR) was used to investigated the functional group of different minerals. Proximate analysis was carried out to determine the surface area of the agro wastes before and after modification. Batch experiments were carried out to investigate the effects of the oil water ratio, temperature, $\mathrm{pH}$ and contact time on the sorption capacities of the adsorbents. Physiochemical characterization of the adsorbents revealed that surface area increased from $114 \mathrm{~cm}^{2}$ to $190.5 \mathrm{~cm}^{2}$ after modification. SEM and FTIR results revealed that more micro porous surfaces were created on the surface of the adsorbent after modification. Batch adsorption experiments with esterified ogbono shell revealed that $96 \%$ of crude oil was removed at a $\mathrm{pH}$ of 5 with oil water ratio of $1.4 / 100 \mathrm{~cm}^{3}$ after $50 \mathrm{~min}$ at a temperature of $90^{\circ} \mathrm{C}$. Esterified ogbono shell was found to be a good adsorbent for the removal of oil layer from polluting water surface.
\end{abstract}

DOI: https://dx.doi.org/10.4314/jasem.v23i9.20

Copyright: Copyright (C) 2019 Onwu et al. This is an open access article distributed under the Creative Commons Attribution License (CCL), which permits unrestricted use, distribution, and reproduction in any medium, provided the original work is properly cited.

Dates: Received: 03August 2019; Revised: 05 September 2019; Accepted: 21 September 2019

Keywords: Biomass waste, Ogbono Shell, Adsorption, Crude oil removal

In recent times, water pollution of seas and underground water has been a growing concern for many countries most especially Nigeria. The major causes of pollution of water surface and underground water has been traced to oil spills (Baars, 2002). Oil spills could be due to release of oil or its derivatives like diesel, petrol, lubricating oil etc from tankers and underground pipes due to breakage occasioned by accident (Banerjee et al, 2006). Investigation on the use of agricultural waste (agro-waste) for the removal of oil from aqueous solutions has been on the increase. Some of these waste materials are available at no cost, naturally occurring, stable and require minimum care or maintenance (Ali et al., 2012; Annunciado et al., 2005). The use of agricultural adsorbents seems to have been recognized as an effective and remarkable control measure in many oil spill situations (Olufemi et al., 2014, Uzoije et al., 2011). Oil pollution of the water bodies and underground water requires urgent attentions due to their environmental and economic importance (Reza et al., 2013; Annunciado et al., 2005). Aquatic animal species respond differently to crude oil or its derivative products pollution in water. However, the crude oil spills in an aquatic environment floats and block out sunlight initiating the death of phytoplankton and seaweed, sources of food and indeed the chief sources of food chains, therefore causing starvation to lives living under the water (Uzoije et al., 2011; Gwendoline, 2010). Nowadays, there has been a tremendous attention regarding the treatment of water and polluted water has been on the increase. However, the most frequent method of water treatments including flocculation, ultra filtration, biological treatment and coagulation (Suidan et al., 2005; Ayotamuno et al., 2006; Yang et al., 2006) suffer from draw back such as high capital, operational cost, time consumption, equipment complexity and the disposal of the residual sludge and do not seen to be economically viable (Uzoije et al., 2011). Adsorption offers the best solution since the process is cheap and faster coupled with the fact that sophisticated equipment are not required for the experiments and the overall process is eco-friendly (Ilaboya et al.,2013) In recent years, natural and organic sorbents synthesized from peat moss, wood, cotton, rice straw, corncobs and kapoks have been identified as an effective sorbents in oil spill treatment (Nwadiogbu et al., 2016). Ogbono shell is an agro wastes gotten after 
removing the ogbono seed It is found mostly in southern part of Nigeria of which are predominantly in south east Nigeria. It is available at no cost. Therefore, this research is aimed at investigating the oil adsorption capacity of ogbono shell modified with organic acid.

\section{MATERIALS AND METHOD}

Materials: Ogbono shells were collected from Akpoga Nike in Enugu State Nigeria. The shells were first washed and dried under the sun for one week. After which, the shells were grinded using a commercial grinder at Oye Market in Emene, Enugu State. Other materials used included; Crude oil, distilled water, sodium hydroxide $(\mathrm{NaOH}), \mathrm{H}_{2} \mathrm{SO}_{4}, \mathrm{HCl}$, Sieving net, stearic acid, n-hexane.

Methods: Preparation of Carbonized Adsorbent (Ogbono Shells): The dried biomass (Ogbono shells) was carbonized in a muffle furnace at $600^{\circ} \mathrm{C}$ for $4 \mathrm{~h}$ respectively. After the carbonization, the samples were cooled and stored in dry transparent containers for further use (Angelova et al., 2011).

Modification of the carbonized samples by esterification: $20 \mathrm{~g}$ of the carbonized ogbono shells were treated with $0.4 \mathrm{~g}$ of fatty acid (stearic acid) in $200 \mathrm{ml}$ of n-hexane containing two drops of concentrated $\mathrm{H}_{2} \mathrm{SO}_{4}$ as catalyst. The mixture was refluxed in dean stark apparatus at $65 \pm 2{ }^{\circ} \mathrm{C}$ for $4 \mathrm{~h}$. After reaction, the esterified acid-biomass was washed severally with $n$ - hexane. The fatty biomass was oven dried at $110^{\circ} \mathrm{C}$ for $12 \mathrm{~h}$ respectively (Banerjee et al., 2006). They were then kept in dry tightly closed bottle for further use.

Weight percentage gain $=\frac{\text { Weight gain }}{\text { original weight }} \times 100$

Characterization of the raw and modified biomass: The surface morphology of the (raw and modified) biomass was studied using Model 302 Hitachi High Field Emission Scanning Electron Microscope and the images at $1 \mathrm{~mm}$ and 150 magnifications. The method employed by Nwabanne and Igbokwe (2008) was adopted to carry out Fourier Transformed Infrared analysis of raw and modified biomass (Ogbono shell) using BUCK model $500 \mathrm{M}$ infrared spectrophotometer. The sample was prepared using $\mathrm{KBr}$ and the analysis was done by scanning the sample through a wave number range of 500 to $4000 \mathrm{~cm}^{-1}$. The proximate analysis parameters and the method of analysis were according to the American Society for Testing and Materials (ASTMD 5142, 3174, 872 and 3175 for moisture, ash, volatile and fixed carbon respectively) (Diadem, 2012)
Adsorption Experiment: The sorption of crude oil contaminated water was carried out following the method described by Banergee et al. (2006). Exactly $50 \mathrm{ml}$ of water was measured inside a $100 \mathrm{ml}$ beaker. A certain amount of crude oil (0.1-1.4g) depending on the oil/water ratio for a particular run was added into the beaker. The oil/water mixture was manually stirred at varying minutes to ensure proper dispersion of the oil in water. $0.2 \mathrm{~g}$ of the modified adsorbent was weighed into the beaker. The beaker containing the sorbent, oil and water was put into a water bath at a varying temperature. The mixture was stirred for a period of time, depending on the particular run. After which the mixture was filtered through a net of approximately $250 \mu \mathrm{m}$. The weight of the net before and after the filtration was recorded. Meanwhile, the net after the filtration was allowed to stay for 24hours before the final weight was taken.

Percentage removal was also calculated according to the equation below

$$
\begin{gathered}
\% \text { removal }=\frac{(\mathrm{Co}-\mathrm{Ce})}{\mathrm{Co}} \times 100 \\
\mathrm{qe}=\frac{(\mathrm{Co}-\mathrm{Ce})}{\mathrm{M}} V
\end{gathered}
$$

$\mathrm{C}_{\mathrm{o}}=$ Initial oil concentration $(\mathrm{mg} / \mathrm{l}) ; \mathrm{C}_{\mathrm{e}}=$ Equilibrium Concentration oil at certain time; $\mathrm{Qe}=$ Equilibrium adsorption in $(\mathrm{mg} / \mathrm{g}) ; \mathrm{V}=$ Volume of the aqueous mixture in $\mathrm{cm}^{3} ; \mathrm{M}=$ Mass of the activated biomass (esterified ogbono shell) in (g)

\section{RESULTS AND DISCUSSION}

Proximate analysis of the raw and modified biomass:The characteristics of raw and modified biomass were shown in Table 1. From the Table, it can be seen that the raw biomass (ogbono shell) have low fixed carbon, surface area and high volatile content and as such suggest that the sample requiresactivation. Increase in fixed carbon and reduction in volatile matter of the activated biomass shows that activation improved the surface area of the biomass for adsorption.

As observed from table 1, the surface area of ogbono shells increased from $114 \mathrm{~cm}^{2}$ (raw ogbono shell) to $190.5 \mathrm{~cm}^{2}$ (Esterified ogbono shell) after modification with strearic acid thereby increasing the number of micropores within the surface the biomass for oil sorption and further validates the effectiveness of biomass modification by esterification and ogbono shells as a good sorbent for oil removal. Similar results on acetylated ogbono shell $\left(199.3 \mathrm{~cm}^{2}\right)$ has been reported by Alothman et al., (2011) 


\begin{tabular}{llllll}
\multicolumn{6}{c}{ Table 1: Physical properties of the raw and modified ogbono shell } \\
\hline Adsorbents & $\begin{array}{l}\text { Ash } \\
\text { content } \\
(\%)\end{array}$ & $\begin{array}{l}\text { Volatile } \\
\text { matter } \\
(\%)\end{array}$ & $\begin{array}{l}\text { Carbon } \\
\text { content } \\
(\%)\end{array}$ & $\begin{array}{l}\text { Surface } \\
\text { area }\left(\mathrm{m}^{2} / \mathrm{g}\right)\end{array}$ & $\mathrm{pH}$ \\
& 7.4 & 28.6 & 56.5 & 114 & 6.9 \\
\hline Raw ogbono shell & 5.7 & 21.4 & 64.2 & 129.4 & 7.1 \\
Carbonized ogbono shell & 5.6 & 19.3 & 69.4 & 190.5 & 7.2 \\
\hline
\end{tabular}

SEM Analysis Results: SEM Analysis is used to study the morphological compositions of the biomass before modification and after modification. There were more pore spaces in the carbonized and activated adsorbents than in the unmodified biomass. Availability of pore spaces favours adsorption process since it is a surface reaction. The surface morphologies of the raw biomass (Ogbono shells), carbonized biomass, and esterified biomass were presented as shown in fig 1 to 3 . It was observed from fig 1 that the samples were internally bonded together. It can be observed from the figures that a bulk of microstructure which in turn is composed of a homogeneously distributed network comprised of small filamentous and fistulous crystallites showing the presence of minerals. In the matrix, Luminous and non-luminous features can be seen.
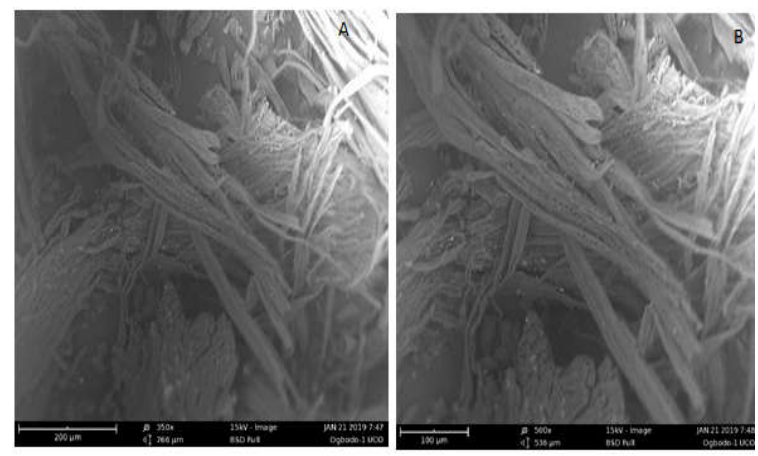

Fig 1: SEM image of un-carbonized ogbono shell @ 200 $\mu \mathrm{m}$ and $100 \mu \mathrm{m}$

These features indicate the presence of minerals distributed in the organic matrix and as surface coverage. It was observed from fig 2 that the crystals and the islands were more compact and shrinks indicating the removal of volatile organics due to action of heat that broke the bonds and was able to remove the volatile matters and opened the pores thereby increasing the adsorption surface area. From fig 3 , the surface is loosed and some features such as fissures, cleats, cracks and veins can be seen showing that the action of heat and acid did lots of harm to the surface and the surface is no longer as intact as shown in fig 1. Some minute fissures and cracks, however an evident. These changes in microstructures may not be unconnected to the removal of some minerals from the activated biomass thereby increasing the micro porous surface. The surface is bright and mostly protracted.
That micrograph reveals that the activation has undergone properly. The porosity has been increased and provides strong evidence that significant amounts of organic elements are being removed thereby increasing the number of micro pores

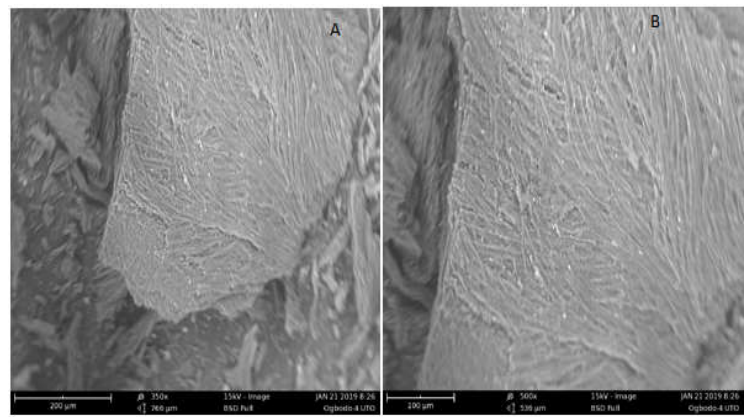

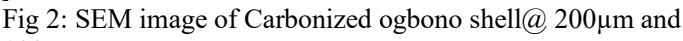
$100 \mu \mathrm{m}$

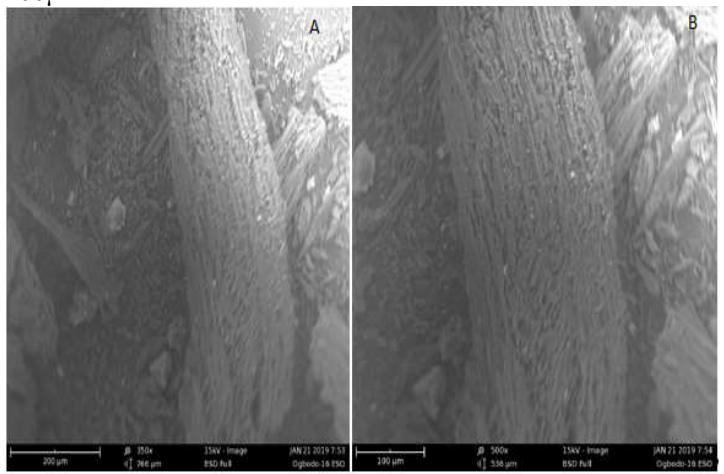

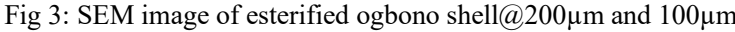

Fourier Transform infrared (FTIR) of the modified and unmodified biomass:Bands were assigned according to the published article (Starsinic et al., 1984; Supaluknari et al., 1998). Fourier transforms infrared spectra of the raw biomass, carbonized biomass, and esterified biomas are presented in Fig 4 to 6 . The frequencies were assigned to the respective functional ground, interpreted and summarized in Table 2. From Table 2, it was observed that the biomass samples have numerous functional groups and the major functional groups present are $\mathrm{O}-\mathrm{H}, \mathrm{N}-$ $\mathrm{H}, \mathrm{N}-\mathrm{CH}_{3}, \mathrm{C}=\mathrm{C}-\mathrm{C}, \mathrm{C}-\mathrm{Cl}$, Si-O-Si. Petroxides bands stretches between $9650-1095 \mathrm{~cm}^{-1}$, Aromatic phosphate P-O-C stretches between $1300-1390 \mathrm{~cm}^{-1}$, Aromatic C-H in plane bend, Silicon oxy compounds $\mathrm{Si}-\mathrm{O}-\mathrm{Si}$ stretches between $1125-1295 \mathrm{~cm}^{-1}, \mathrm{C}-\mathrm{Cl}$ stretch, alkyne C-C bend lies between $700-900 \mathrm{~cm}^{-1}$, hydroxyl group $\mathrm{OH}$ stretch was observed between

ONWU, DO; OGBODO, ON; OGBODO, NC; CHIME, TO; UDEH, BC; EGBUNA, SO; ONOH, MI; ASADU, 
$4000-3650 \mathrm{~cm}^{-1}$, primary amine group NH stretches between $3200-3450 \mathrm{~cm}^{-1}$, Aliphatic secondary amine $\mathrm{NH}$ stretches between $3150-3200 \mathrm{~cm}^{-1}$, Normal polymetric stretch of hydroxyl group lies between 3050-3100 $\mathrm{cm}^{-1}$,Methylamino acids $\mathrm{N}-\mathrm{CH}, \quad \mathrm{C}-\mathrm{H}$ stretches between $2550-2950 \mathrm{~cm}^{-1}$, Cyanide ion, thiocyanide ion stretches between $1990-2000 \mathrm{~cm}^{-1}$, Isocyanate $\mathrm{N}=\mathrm{C}=\mathrm{O}$ stretches between $2290-2550 \mathrm{~cm}$ 1 , Isothiocynate -CNS bond stretches between 1600$1795 \mathrm{~cm}^{-1}$, Conjugated keton, open chain acids anhydrides stretches between $1600-1750 \mathrm{~cm}^{-1}$, the bending of the hydroxyl group was further observed at the stretch between $1450-1595 \mathrm{~cm}^{-1}$. Fig 4 showed that the entire spectrum had more or less similar broad characteristic absorption bands.

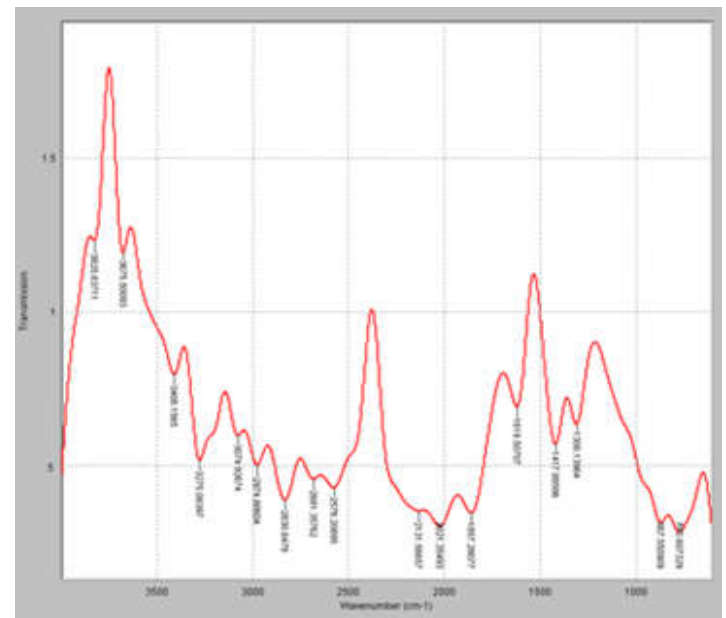

Fig 4: FTIR spectra for uncarbonizedogbono shell

All the absorption bands were unresolved indicating that the material constituents had either large particle size or a contained polymeric unit which shows that the volatile matter is still intact. Esterification of the carbonized biomass has better modification with removal of volatile matter thereby creating more pores for oil adsorption as shown in fig 6 indicating that the picks are more resolved than the picks as shown in Fig 4 , this further proved that esterification is effective in removing volatile matter and increasing micro pores on the surface of the adsorbents. The change in absorption and frequency in the spectrum peaks shows how the several treatment conditions affect the structure of the biomass .The functional groups indicate that the biomasses are organic compound which are hydrophobic and olephilic. This could be the reasons while they were able to remove the oil from water surface.Upon comparing the spectrum; it was observed that all the samples showed a remarkable absorption near $1440 \mathrm{~cm}^{-1}$. This indicated the strong presence of ethylene and methyl groups in the samples. The bands at $1541 \mathrm{~cm}^{-1}$ and $1442 \mathrm{~cm}^{-1}$ is normally present in organic substance (biomass) with more Lignin content. The band was shifted from strong absorption to medium intensity in the spectra of stable product. This reveals the effectiveness of modification of biomass using esterification.

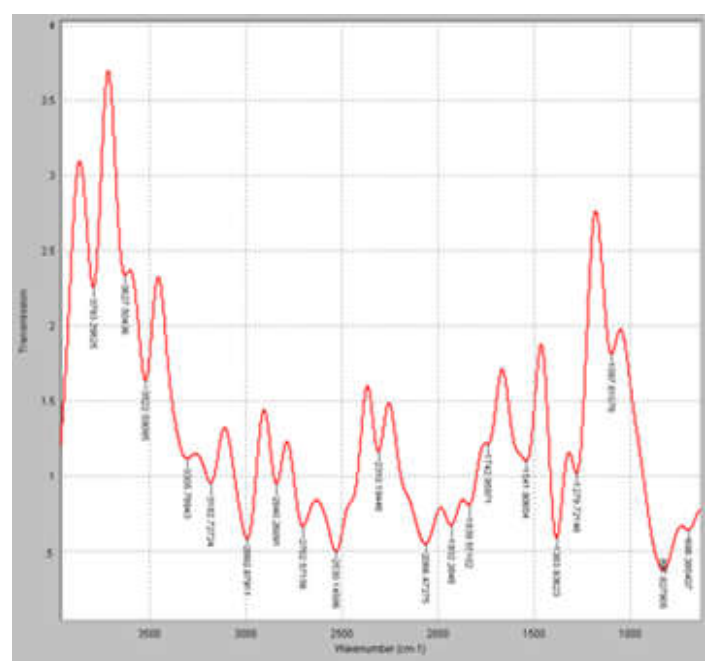

Fig 5: FTIR spectra for carbonized ogbono shell

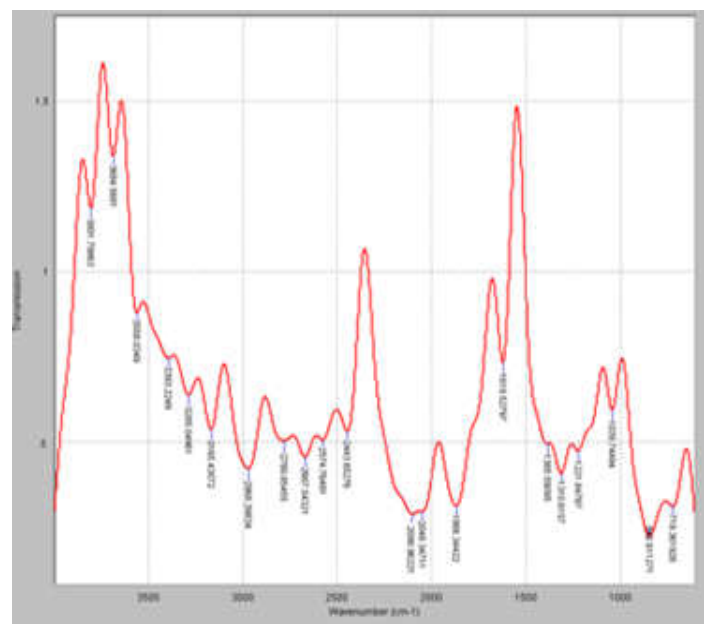

Fig 6: FTIR spectra for esterified ogbono shell

Batch adsorption Studies: Changing different parameters, such as $\mathrm{pH}$, oil/ water ratio, contact time, and temperature at constant adsorbent dosage, the adsorption capacity of the activated ogbono shell was investigated.

Effect of oil/water ratio and time: The initial concentration of oil layers within the polluted water surface determines the amount that will be absorbed into the micro pores with the surface of a given amount of adsorbent (Bhatia et al., 2007; Brandao et al., 2010). Hence the effect of oil water ratio was studied for the initial oil concentration ranging from 0.2 to $1.4 \mathrm{~g} / 100 \mathrm{~cm}^{3}$ and the results were presented in Fig 7 . The figure shows that increase in concentration of oil 
on the surface of water decreases the rate of adsorption of oil by the biomass with increase in time.

Table 2: FTIR spectrum of modified and unmodified ogbono shell

\begin{tabular}{|c|c|c|c|}
\hline $\begin{array}{l}\text { Raw or } \\
\text { uncarbonized } \\
\text { Qabong shell }\end{array}$ & $\begin{array}{l}\text { Carbonized } \\
\text { Or untreated } \\
\text { ogbono shell }\end{array}$ & $\begin{array}{l}\text { Esterified } \\
\text { gabsno } \\
\text { shell }\end{array}$ & Assignment \\
\hline $\begin{array}{l}\text { Frequency } \\
\left(\mathrm{cm}^{-1}\right)\end{array}$ & $\begin{array}{l}\text { Frequency } \\
\left(\mathrm{cm}^{-1}\right)\end{array}$ & $\begin{array}{l}\text { Frequency } \\
\left(\mathrm{cm}^{-1}\right)\end{array}$ & Assignment \\
\hline $\begin{array}{l}3825.637- \\
3675.501\end{array}$ & $\begin{array}{l}3793.298 \\
3627.504\end{array}$ & $\begin{array}{l}3801.977- \\
3684.566\end{array}$ & $\mathrm{O}-\mathrm{H}$ stretch \\
\hline- & 3522.591 & 3558.035 & $\begin{array}{l}\text { Hydroxyl group, H-bonded, O-H } \\
\text { stretch }\end{array}$ \\
\hline 3408.157 & 3305.789 & 3393.225 & $\mathrm{NH}$ stretch \\
\hline 3275.084 & 3182.727 & $\begin{array}{l}3165.436 \\
3285.05\end{array}$ & $\begin{array}{l}\text { Aliphatic secondary amine, } \mathrm{NH} \\
\text { stretch }\end{array}$ \\
\hline 3074.927 & - & 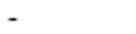 & Normal "polymeric" OH stretch \\
\hline $\begin{array}{l}2576.209- \\
2974.886\end{array}$ & $\begin{array}{l}2530.146 \\
2992.879\end{array}$ & $\begin{array}{l}2574.765- \\
2968.398\end{array}$ & Methulamino, N-CH3, C-H stretch \\
\hline- & 2310.194 & 2443.553 & Isocypanate $(-\mathrm{N}=\mathrm{C}=\mathrm{O}$ asym. Stretch) \\
\hline $\begin{array}{l}2021.355- \\
2131.567\end{array}$ & 2066.473 & 2048.347 & $\begin{array}{l}\text { Cynaide ion, thiocyonanate ion and } \\
\text { related ions }\end{array}$ \\
\hline & 1932.285 & - & Isothiocynanate (-NCS) \\
\hline 1857.261 & 1839.551 & 1866.344 & $\begin{array}{l}\text { Conjugated ketone, open-chain acid } \\
\text { anhydride }\end{array}$ \\
\hline 1619.507 & 1742.96 & 1619.528 & $\mathrm{C}=\mathrm{C}-\mathrm{C}$ Aromatic ring stretch \\
\hline- & 1541.907 & - & $\mathrm{O}-\mathrm{H}$ bend \\
\hline 1417.886 & - & - & N-O asymmetric stretch \\
\hline 1308.14 & 1383.936 & $\begin{array}{l}1310.616 \\
1385.591\end{array}$ & Aromatics phosphates (P-O-C stretch) \\
\hline- & 1279.721 & 1221.848 & $\begin{array}{l}\text { Aromatic } \mathrm{C}-\mathrm{H} \text { in plane bend, Silicon- } \\
\text { oxy compounds, } \mathrm{Si}-\mathrm{O}-\mathrm{Si}\end{array}$ \\
\hline - & 1097.611 & 1039.745 & Peroxides, $\mathrm{C}-\mathrm{O}-\mathrm{O}$ - stretch \\
\hline 867.5509 & 827.8279 & 842.6113 & C-Cl stretch, Alkyne C-H bend \\
\hline 770.6973 & - & 719.3619 & $\mathrm{C}-\mathrm{Cl}$ stretch, Alkyne C-H bend \\
\hline- & 698.3854 & - & C-Sl stretch, Alkyne C-H bend \\
\hline
\end{tabular}

That is, there was decrease in percentage sorption as the crude oil concentration increases. This could be that the porous surfaces of biomass (adsorbents) available for the removal (adsorption) of oil were becoming saturated as the crude oil concentration increases. While the amount oil adsorbed (removed) per unit mass increased with increase in initial oil concentration, the adsorption percentage decreased, this can be explained because at lower concentration, the ratio of the initial number of the oil molecules to the available surface area is low (Arivoli et al, 2009). Because for a fixed concentration of active sites remaining the same, the number of substrates ions accommodated in the interlayer space increased so that the removed ones is decreased. This may be due to the fact that with increase in initial concentration of the oil, more oil molecules are also adsorbed on the surface of the biomass (adsorbent). Similar results were obtained by many workers such as (Cheenmatchaya and Kungwakunakorn, 2014; Cojocaru et al., 2011; Cunha et al., 2011). Initially, the highest average percentage of $75.2 \%$ oil layer was absorbed with concentration of $1.4 \mathrm{~g} / 100 \mathrm{~cm}^{3}$ after 10 minutes but decreased progressively with increase in time. This is because the amount of oil adsorbed per unit time at the beginning of the process is significantly influenced by the initial concentration of oil (Deschamps et al., 2003).

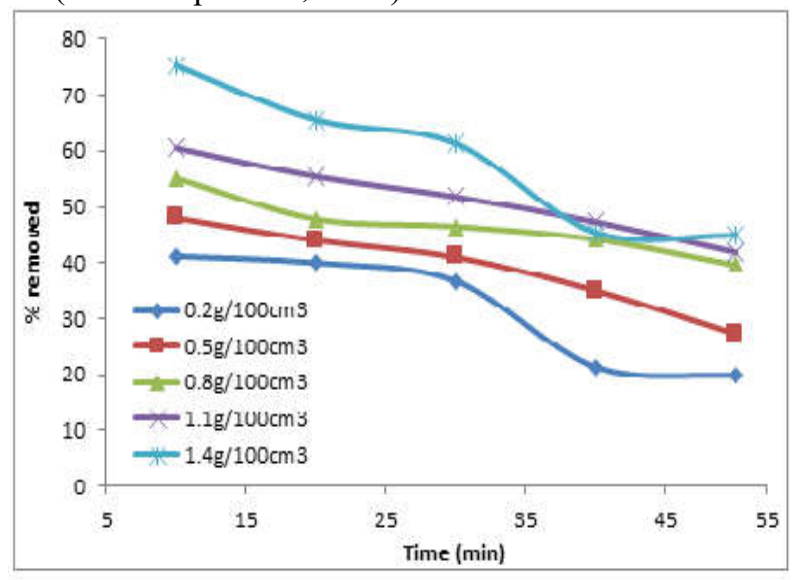

Fig 7: Effect of oil/water ratio and time on oil sorption

Effect of $p H$ and time: The effect of $\mathrm{pH}$ at 3, 5, 7, 9 and 11 and time of 10, 20, 3040 and 50 mins is as shown in fig 8 . It could be seen from fig 8 that maximum percentage removal of $96 \%$ oil layers happened at $\mathrm{pH}$ 5.0 after 50 minutes and decreased as the $\mathrm{pH}$ increased up to $\mathrm{pH}$ 11.0. This is because at acidic $\mathrm{pH}$, the degree of protonation of the surface of the activated biomass will be more which will result in increase in diffusion ONWU, DO; OGBODO, ON; OGBODO, NC; CHIME, TO; UDEH, BC; EGBUNA, SO; ONOH, MI; ASADU, 
and subsequently increase in oil removal (adsorption) due to electrostatic attraction (Ladhe et al, 2011; Pragnesh et al, 2011). The decreases in percentage removal of oil from $\mathrm{pH} 7$ and above could be also due to the fact that oils are prototypical apolar solvents. Also, this could be due to the number of positively charged adsorbent sites decreasing as the $\mathrm{pH}$ increased. This causes the number of negatively charged surface sites to increase which did not favor the adsorption of negatively charged oil cations due to electrostatic repulsion This agrees with the report by Bansal et al.,(2011) which state that oil is non-polar as it consists of non-polar bonds which repels atoms having similar electro negativities and with net dipole.

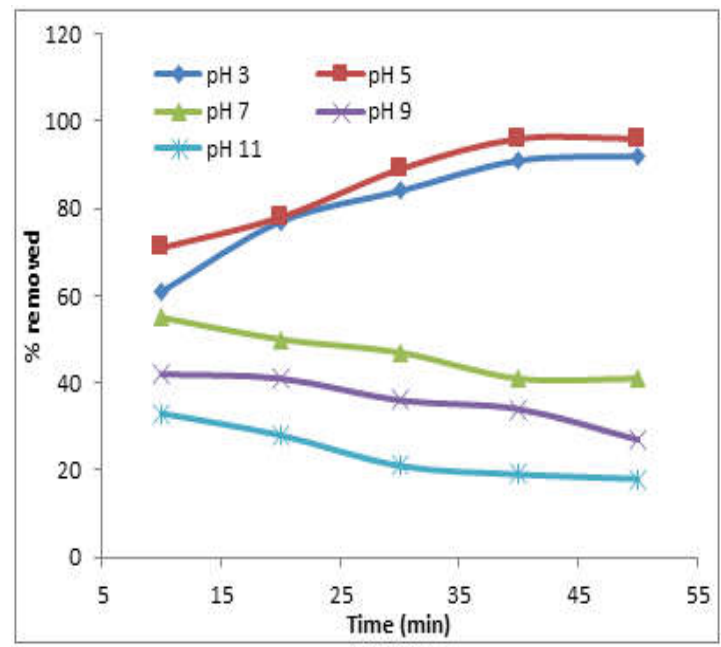

Fig 8: Effect of $\mathrm{pH}$ on the adsorption of oil layer from water surface

Effect of temperature and time: Temperature values of $30,50,70$ and $90^{\circ} \mathrm{C}$ were used to study the effect of temperature on the removal oil from water surface using the esterified activated biomass (ogbono shell) and the results were as shown in fig 9. It was observed that with increase in temperature; the time to achieve the same percentage sorption of oil from surface water was much less. This is because as the temperature increased, the rate of diffusion of oil molecules across the external boundary layer and internal pores of the activated biomass (adsorbent) particles increased (Shahawanet al, 2002). Fig 9 shows that the optimum temperature for the removal (sorption) of oil using ogbono shell occurred at $70^{\circ} \mathrm{C}(343 \mathrm{~K})$ with highest percentage removal of $87.3 \%$ after 50 minutes, thereafter the percentage sorption significantly decreased to $40.7 \%$ with further increase in temperature at $90^{\circ} \mathrm{C}(363 \mathrm{~K})$ after 50 minutes. Apart from temperature from $90^{\circ} \mathrm{C}$ and above, the sorption of oil by the activated ogbono shell at 30,50 , and $70^{\circ} \mathrm{C}$ were progressively directly proportional to increase in temperature and time as shown in figs 9. Temperature affects the rate of removal of oil by altering the molecular interactions and the solubility of the oil. The removal of oil with increase in temperature would increase the mobility of the oil molecules and produce a swelling effect within the internal structure of adsorbent.

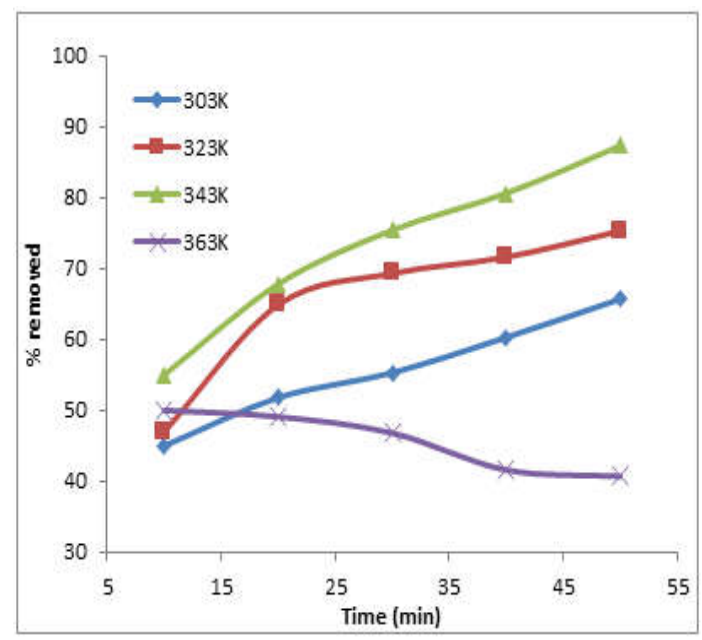

Fig 9: Effect of temperature and time on oil layer sorption from water surface.

Conclusion: Analysis of data in this investigation showed that carbonized ogbono shell modified by esterification with steric acid can be used as economic, effective and eco-friendly adsorbents for the maximum removal of crude oil from water surface. FTIR analysis of activated and uncarbonized biomass (ogbono shell) shows that they consist mainly of organic compounds such as hydroxyl group, amino group, amine and conjugated ketones.

\section{REFERENCES}

Ali, N., El-Harbawi, M., Jabal, A., A., Yin, C., Y (2012) Characteristics and Oil sorption effectiveness of kapok fibre, sugarcane bagasse and rice husks: oil removal suitability matrix. Environ. Technol.33 (4), 481-486

Annunciado T.R., Sydenstricker T.H.D., Anuco S.C.; (2005). Experimental Investigation of Various Vegetable Fibers as Sorbent Materials for Oil Spills Mar. Pollute. Bull. 50, 13040-13046.

Ayotamuno M.J., Kogbara R.B., Ogafi S.O.T., Probert S.D., (2006). Bioremediation of a Crude Oil Polluted Agricultural-Soil at Port-Harcourt. Nigeria J. Appl. Energy 83, 1249-1257.

Angelova, D., Uzonov, I., Uzonova, S., Gigova, A., Minchev, L., (2011). Kinetics of oil and oil 
product adsorption by carbonized rice husks, Chemical Engineering Journal, 172(1), 306-311.

Alothman, Z.,A, Habila, M., A., \& Ali, R.,(2011). Preparation of activated carbon using the copyrolysis of Agricultural and municipal solid waste at a low carbonization temperature. Internal conference on biology environment and chemistry. 1PCBEE vol.24

Arivoli, S., Hema, M. and Martin, P. D. (2009) Adsorption of malachite green onto carbon prepared from borassus bark. The Arabian Journal for Science and Engineering, 34(2A), 31-43

Baars, B., J.,(2002). The wreckage of the oil tanker 'Erika'-human health risk assessment of beach cleaning, sunbathing and swimming, Toxicology Letter, 128 (1-3), 55-68.

Banerjee, S., S., Joshi, M., V., Jayaram, R., V.,(2006). Treatment of oil spill by sorption technique using fatty acid grafted sawdust. Journal of Chemosphere, 64, 1026-1031.

Bhatia, S., Othman, Z., Ahmad, A., L.,(2007). Coagulation-flocculationprocess for POME treatment using Moringaoleifera seeds extract: optimization studies. Chemical Engineering Journal, 133 (1-3), 205-212.

Brandao, P., C., Souza, T., C., Ferreira, C., A., Hori, C., E., Romanielo, L., L.,(2010). Removal of petroleum hydrocarbons from aqueous solution using sugarcane bagasse as adsorbent. Journal of Hazardous Materials, 175, 1106-1112

Bansal, S., Arnim, V., V., Stegmaier, T., Planck, H., (2011). Effect of fibrous filter properties on the oil-in -water emulsion separation and iltration performance. Journal of Hazardous Material,190(1-3), 45-50.

Cheenmatchaya, A. \&Kungwakunakorn, S. (2014). Preparation of Activated Carbon Derived from Rice Husk by simple Carbonization and Chemical Activation for Using as Gasoline Adsorbent. International Journal of Environmental Science and Development, 5(2), 21-33.

Cojocaru, C., Macoveanu, M., Cretescu, I.,(2011). Peat-based sorbents for the removal of oil spills from water surface: Application of artificial neural network modeling.Colloids and Surfaces A: Physicochemical and Engineering Aspects, 384, 675-688.
Cunha, M. A. E., Neves, R.,F., Souza, J.,N.,S., Franca, L.,F., Araujo, M.,E.,G., Brunner, N.,T (2011). Machado, Supercritical adsorption of buriti oil (Mauritiaflexuosa Mart.) in calumina:a methodology for the enriching of anti-oxidants. Journal of Supercritical Fluids, 1-11.

DidemÖzçimen (2012). An Approach to the Characterization of Biochar and Bio-Oil Bioengineering Department Yildiz Technical University, Turkey

Deschamps G., Caruel H., Borredon M.E., Bonnin C., Vignoles C., (2003). Oil Removal from Water by Selective Sorption on Hydrophobic Cotton Fibers: Study of Sorption Properties and Comparison with other Cotton Fiber-based Sorbents. Environmental Science Technology, 37 (5), 1013-1015.

Gwendoline F., (2010). The Effects of Oil Spills of Aquatic Life and Environments. Journal Science Natural, 2 (4), 23-30.

Ilaboya I.R., Oti E.O., Ekoh G.O. and Umukoro L.O. (2013). Performance of Activated Carbon from cassava peels for the treatment of Effluent Wastewater. Iranica Journal of Energy \& Environment. 4: $361-375$.

Ladhe, U. V., Wankhede, S. K., Patil, V. T. and Patil P. R. (2011). Adsorption of eriochrome black-T from aqueous solutions on activated carbon prepared from mosambi peel. Journal of Applied Sciences in Environmental Sanitation, 6(2), 149154.

Nwadiogbu J.O., Ajuwe V.I.E., Okoye P.A.C., (2016). Removal of Crude Oil from Aqueous Medium by Sorption on Hydrophobic Corncobs: Equilibrium and Kinetic Studies. Journal of Taibah University for Science, 10, 56-63.

Nwabanne J., T., \&Igbokwe, P. K., (2008). Copper (II) uptake by adsorption using palmyra palm nut. Advances in Applied Science Research, 2(6), 166-175.

Olufemi, BA, Jimoda LA and Agbodike NF. (2014). Adsorption of Crude Oil using Meshed Corncobs. AsianJournal of Applied Science and Engineering, 3, 63-75.

Pragnesh, N. D., Satindar, K. and Ekta, K. (2011) Removal of eriochrome black $-\mathrm{T}$ by adsorption onto eucalyptus bark using green technology.

ONWU, DO; OGBODO, ON; OGBODO, NC; CHIME, TO; UDEH, BC; EGBUNA, SO; ONOH, MI; ASADU, 
Indian Journal of Chemical Technology 18, 5360.

Reza B., Bagher A., (Nematollah J.H.F., Masoumeh F., (2013). Application of Natural Sorbents in Crude Oil Absorption. Iranian J. Oil and Gas Sci. Technol. 2, 01-11.

Shahawan, T. and Erten, H. N. (2002), Thermodynamics parameters of $\mathrm{Cs}^{+}$sorption on natural clays. Journal of Radioanalytical and Nuclear Chemistry, 253(1), 115-120.

Starsinic M. Otake Yeshinobu, Walkerjr P.L and Paul C Painter, 1984 "Application of FT - Ir Spectroscopy to the determination of $\mathrm{C} 00 \mathrm{H}$ groups in Coal" Fuel 63 (7).
Supaluknari S., Larkius F.P, Redlech P., Jackson W.K 1998. "An FTIR Study of Australian Coals: Characterization of Oxygen Functional Groups" Fuel Process Technology $19123-140$.

Suidan M.T., Esperanza M., Zein P., McCauley R.C., Brenner A.D., (2005). Challenges in Biodegradation of Trace Organic ContaminantsGasoline Oxygenates and Sex Hormones: Water Environmental Research, 77(1), 4-11.

Uzoije A.P., Onunkwo A., Egwuonwu N., (2011). Crude Oil Sorption Onto Groundnut Shell Activated Carbon: Kinetic and Isotherm Studies. Res. J. Environ. Earth Sci. 3(5), 555-563.

Yang G., Zhang L., Sun X., Jing, W., (2006). Photochemical Degradation of Crude Oil in Sea Water. Chinese J. Oceanol. Limnol. 24(3), 264269. 